Session 3432

\title{
A Novel Structure for Electrical Engineering Senior Capstone Laboratory
}

\author{
Behnam Kamali \\ Mercer University School of Engineering
}

\begin{abstract}
The electrical engineering senior capstone laboratory course is meant "to provide the electrical engineering senior student with additional and varied experiences in creating and designing working electrical/ electronic/ electromechanical systems, from specifications to prototype product". At Mercer University we have structured this course such that in addition to design stipulations, it addresses a number of other EC 2000 requirements, specially, those listed under criterion III; "Program Outcomes and Assessment". In particular, attempts are made to expose the student to a number of important features of engineering profession in the 21 th century. Specifically, three important issues of globalization of engineering practice, the need for lifelong learning, and the role of technical communications skills are addressed in this course. Moreover, the design of an engineering experiment is included in this course. In this article, following a detailed account of the structure of this course, we provide a list of several design projects that have been selected for this course. A sample design project on fabrication and testing of a simple AM radio receiver is described in some detail. Finally, a sample on "Design of an Experiment" is referenced briefly.
\end{abstract}

\section{Introduction}

As the rapid advances in high technologies and global information networking continue, the need for more technologically inclined workforce has produced an ever-increasing demand for traditional and modern engineering skills. Skills such as the capacity to resolve open-ended problems, the ability to engage in life-long learning, the capability of analyzing and interpreting large volumes of data using modern signal processing tools, the understanding of the essentiality of team work (often interdisciplinary team work) in the design of novel hardware and software systems, the proficiency in verbal and oral technical communications, are now expected from practicing engineers. To keep up with these rapid changes and new requirements, and reflect them in the formal electrical engineering education, ABET has assembled a new set of accreditation criteria, the EC 2000. Although the new criteria are less prescriptive than were the old criteria, EC 2000 has embedded many new requirements in criterion III, designated as "Program Outcomes and Assessment". This criterion lists eleven areas in which the student must acquire knowledge, skills, and understanding ${ }^{1}$. We have attempted to address the following areas of criterion III in our EE senior capstone laboratory:

a. an ability to apply knowledge of mathematics, science, and engineering

b. an ability to design and conduct experiments, as well as to analyze and interpret data

c. an ability to design a system, component, or process to meet desired needs 
e. an ability to identify, formulate, and solve engineering problems

g. an ability to communicate effectively

i. a recognition of the need for, and an ability to engage in life-long learning

The main idea behind EE senior capstone laboratory course is "to provide the electrical engineering senior student with additional and varied experiences in creating and designing working electrical/ electronic/ electromechanical systems, from specifications to prototype product". The course provides a platform through which, not only does the student have an opportunity to design small systems, without having to engage in the extensive design documentation, economic analysis, and etc. that is normally required in senior design courses, but also she/he has a chance to address several other issues which are difficult to fit into an engineering program.

\section{The Structure of the Course}

With the new facilities available in our communications/ telecommunications laboratory, the projects proposed by the instructor are mostly centered around RF and radio system design. The selection of design projects is through either assignment or, on occasion, personal choice of the student and approval of the instructor. The student is required to complete three to four projects, selected from the following topics:

1. Design, fabrication, evaluation, and testing of a simple AM radio receiver

2. Design, fabrication, evaluation, and testing of a simple FM radio receiver

3. Design, fabrication, and evaluation of an infrared digital transmitter/ receiver system

4. A DSP project on speech processing and filtering

5. Design of RF amplifiers/oscillators/ converters

6. Step-down (buck), or step-up (boost) DC to DC converter

7. A project on application of microcontrollers/ microprocessors, preferably in communications/ telecommunications area (a list of possible projects is provided by the instructor).

8. A project on the applications of DSP chips, preferably for communications applications.

9. Any project that is proposed by the student and is approved by the instructor.

10. Design of a measurement experiment using various test equipment of the communications laboratory.

The last project, which addresses "an ability to design and conduct experiments, as well as to analyze and interpret data", is a required part of the course. The Mercer University communications laboratory is equipped with the-state-of-the-art test equipment ${ }^{2}$, such as Tektronix 420 series and 700 series sampling scopes, Tektronix 2711 Spectrum Analyzer, Tektronix/ Sony AWG series Arbitrary Waveform Generators, HP 53310A Modulation Analyzer, that are all menu-driven systems with extensive user's and programming manuals. After a few hours of search in these manuals, the student should be able to come up with an idea for a measurement experiment.

The grade for circuit /system design is determined based on the quality of design, the quality of implementation, team work, timely submission, and a brief report. Grading for experiment 
design is based on validity of the experiment, significance of the experiment, accuracy of the experiment, and report.

For the final examination it is required that the student search through IEEE magazines as well as a selected group of trade magazines and find a tutorial source article on a topic in electrical/ electronic/ communications technologies that they have no familiarity with. Topics that were suggested by the instructor, as examples, included computer telephony, GPS, CDPD and other wireless data networks, wireline and wireless ATM networks, and wireless access to Internet. The final examination consists of two parts; a paper that will be prepared on the student's selected topic using the format of IEEE technical papers. In addition to technical content, the paper should address the following questions as well:

1. How do you see the global aspect of the technological development in the area discussed in your paper (or in electrical technologies in general)?

2. Comment on the importance of life-long learning aspect of engineering practice, as it relates to this topic, in the 21 st century.

The second part of the final examination is a 10 to 15 minute oral presentation in class on the selected topic. This will be a structured presentation similar to those of the IEEE technical conferences. This is to expose the student to three important features of engineering practice in the next century, namely, globalization, the need for life-long learning, and the importance of technical communications skills.

\section{A Sample Experiment on Design of a Simple AM Radio Receiver}

The idea of Superheterodyne radio receiver was conceived shortly before the end of WW I. Although the quality of this type of radio receiver has improved due to improvement in electronic circuit technology, the configuration has essentially remained the same to this day. Owing to their gain, selectivity, and sensitivity characteristics that are superior to those of alternative radio receivers, the Superheterodyne receivers are used in wide variety of radio communications. One of the difficulties in designing a Superheterodyne radio receiver, in an academic laboratory setting, is the design of the wideband RF amplifier that amplifies the signal that is received from antenna and filtered by tuning circuit. The implementation of a mixer, that convert RF signals to the IF signal, has also proven strenuous, particularly when analog discrete components are to be used. In order to design a simplified AM radio receiver with limited reception capability, but yet experiment with many essential functions of a commercial AM radio receiver, the student was asked to design a receiver that is capable of tuning to only two neighboring local stations. This receiver does require neither a wideband RF amplifier, nor a RF to IF signal converter. The Automatic Gain Control (AGC) system was also ignored in the receiver. A functional block diagram of this receiver is illustrated in Figure 1. The requirements and specifications of this project are as follows.

1. This receiver should be able to tune to two neighboring local AM stations (different teams are to select different stations).

2. An output power of at least 0.25 Watt is required for each receiver. 
3. The cost should be limited to about $\$ 10$ for each receiver.

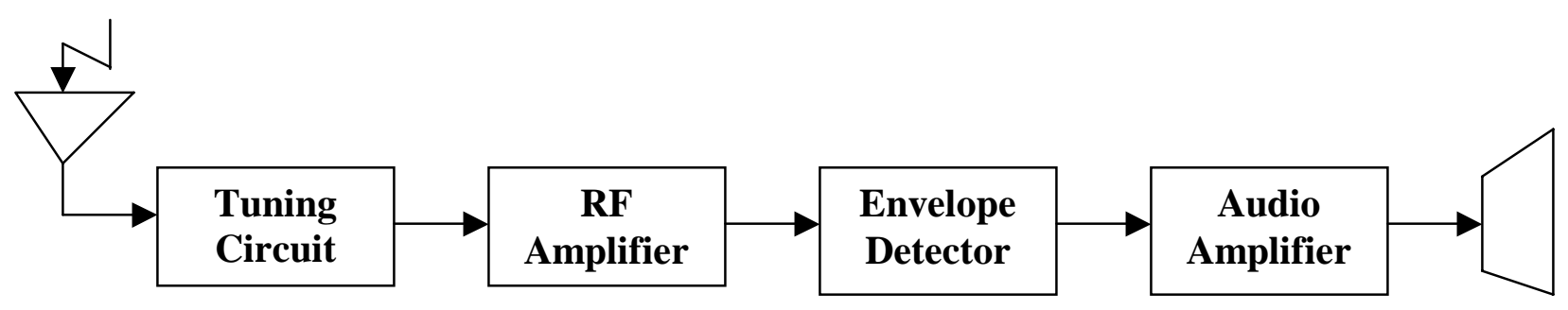

Figure 1: A Possible Block Diagram for a Simple AM Radio Receiver

- You may use the configuration given in Figure 1 or a configuration of your own.

- Any device/ circuit used in this design may have no more than two functions in the system.

- You may use any component that is available in communications lab or you might purchase any number of them from any vendor.

- You are required to devise a method to measure the receiver's output power.

The RF amplifier in Figure 1 is to amplify the signals received from two neighboring AM stations, which requires a bandwidth of about 30 to $40 \mathrm{kHz}$. The tuning circuit separates the two signals, while provides sufficient bandwidth for each signal to transfer through. In this project, in addition to design of the system, the student observes several functions of a Superheterodyne radio receiver (although heterodyning itself is not a part of this system) such as tuning and filtering, amplification, envelope detection, and impedance matching. One other aspect of this project is the need for interfacing of several analog circuits.

\section{A "Design of an Experiment" Sample}

The student is asked to design an experiment to determine the transfer function for a given electronic or electromechanical system.

Bibliography

1. Criteria For Accrediting Engineering Programs, Effective for Evaluations During the 1999-2000 Accreditation Cycle, Engineering Accreditation Commission, Accreditation Board for Engineering and Technology, 111 Market Place, Suite 1050, Baltimore, MD 21202.

2. B. Kamali, Development of an Undergraduate Structured Laboratory to Support Classical and New Base Technology Experiments in Communications. IEEE Transactions on Education, vol. 37, No. 1, February 1994.

\section{BEHNAM KAMALI}

Behnam Kamali is a Professor of Electrical and Computer Engineering at Mercer University. He received a B.S.E.E degree from Tehran Polytechnic in 1972, a M. E. degree from California State Polytechnic University, Pomomna, in 1979, a M. S. E. E degree from Oregon State University in 1981, and the Ph.D. degree in Electrical Engineering

from Arizona State University in 1985. Dr. Kamali is a registered Professional Engineer and a senior member of the IEEE. His teaching and research interests are in Error Control Coding and Wireless Communications Systems. 